\title{
The gray relation entropy research between the stability of emulsified asphalt and chemical components of asphalt
}

\author{
Pinhui Zhao ${ }^{1, a^{*}}$, Dongxing Gao ${ }^{1, b}$, Zeyu Zhang ${ }^{1, \mathrm{c}}$, Kechao Han ${ }^{1, \mathrm{~d}}$, Fei Bi ${ }^{1, \mathrm{e}}$, \\ Ziqiao Yang ${ }^{1, f}$
}

${ }^{1}$ School of transportation Engineering, Shandong Jianzhu University, Jinan 250101, Shandong, China

azhaopinhui08@163.com, bgaodongxing@yahoo.com, czhangzeyu940827@163.com,

dhankechao@163.com, ${ }^{\mathrm{e}}$ bifei931223@126.com, ${ }^{\mathrm{f}} \mathrm{yangziqia0520@126.com}$

Keywords: gray correlation entropy; bitumen; emulsified asphalt; chemical components; stability Abstract. The basic properties, composition, and structure of four base bitumens: A1, A2, A3, and A4 were analysed. The stability of emulsified asphalt was investigated by means of residue content difference tests. The relationships between the stability of emulsified asphalt and the chemical compositions of the chosen bitumen blends were studied by means of gray correlation entropy method using the MATLAB ${ }^{\circledR}$ platform. Furthermore, the relationship between the stability of emulsified asphalt and the chemical composition of the bitumen were also discussed. It was shown that: The contents of resin and asphaltene are important factors in the composition of four-polar fractions in asphalt which affect stability of emulsified asphalt. The higher the resin and asphaltene contents, the better the stability of emulsified asphalt. In the elemental composition of asphalt the heteroatom content is an important factor influencing the stability of emulsified asphalt. Generally higher heteroatom content gives better stability, however, the basic properties and average structural unit parameters of asphalt cannot be used to characterize the stability of emulsified asphalt since they show no obvious correlation.

\section{Introduction}

Highway traffic is a major form of transportation globally, hence all nations attach major importance to the construction of highways at different levels and regular maintenance of paved roads. Therefore, emulsified asphalt and related applications such as micro surfacing, slurry seal, cold-laidcold-mix and preventive maintenance have become important in highway maintenance worldwide. Its advantages include environmental and economic benefits, and good technical performance hence emulsified asphalt is widely used[1,2].

Emulsified asphalt is an oil-in-water emulsion formed by a mechanical mechanism. Hot-melt petroleum asphalt is dispersed in an aqueous solution containing emulsifiers and stabilizers in the form of fine particles. This oil-in-water emulsion is thermodynamically unstable resulting in some undesirable effects[3]. Its production and application, for instance, produces crust, flocculate, stratified oil and water, and agglomerate leading to unnecessary problems in highway construction. The stability is therefore regarded as the most important performance index for emulsified asphalt[4].

Considerable research has been conducted on the factors affecting stability of emulsified asphalt. This includes type and amount of emulsifier and promoter, preparation technology condition of emulsified asphalt, the construction conditions including temperature and stirring process, and type and property of aggregates[4,9]. Very little research has been carried out on the influence of components and properties of asphalt on emulsified asphalt performance. Owing to poor universality 
of asphalt and emulsifier, significant differences in performances in the construction and application have been found using emulsified asphalts prepared by different asphalts. In this paper the influence of asphalt with different components and properties on the stability of emulsified asphalt has been investigated, with the aims of determining the performance differences in emulsified asphalts prepared by different asphalts.

\section{Materials and methods}

\section{Chemical reagents and materials}

The emulsifier used in the experiments was a cationic amide emulsifier (MQK-1D) acquired from MWV, USA. The four types of base bitumen (AH-70) used were:A1、A2、A3、A4. The toluene, nheptane, petroleum ether, ethanol, and hydrochloric acid used were all analytically pure grades.

\section{Instruments}

A PHS-3C $\mathrm{pH}$ meter was used to determine the $\mathrm{pH}$ of both the water and the bitumens. The elemental analyses of the samples was carried out by conventional combustion method using a Perkin-Elmer CHN analyser. The oxygen content was obtained by subtraction. ${ }^{1} \mathrm{H}$ NMR spectra were obtainedfor that fraction insoluble in n-heptane as obtained at different temperatures; these fractions were re-dissolved in $\mathrm{CDCL}_{3}$ containing a trace amount of tetramethylsilane(TMS), which was used as an internal chemical shift reference. All spectra were obtained using a Burker AMX 300 spectrometer, using a $5 \mathrm{~mm}$ inner diameter sample holder.The average molecular weight was measured by vapour pressure osmometer (type K-7000, Knauer, Germany). Modified asphalt /emulsified asphalt equipment developed by DALWORTH laboratory (USA) was used forproducing emulsified asphalt. The storage stability of emulsified asphalt wasdetermined using SYD-0655 emulsified asphalt storage stability tester and Brookfield rotational viscometer was used to measure the viscosity.

\section{Separation and characterisation of the bitumen}

The bitumen was separated into four components according to their polarizability and polarity; asphaltene was removed by precipitation with n-heptane and the deasphalted oil was separated into saturate, aromatic, and resin components by chromatographic separation[10]. The process of SARA separation was carried out with reference to "NB/SH/T 0509-2010 Test method for separation of asphalt into four fractions".

\section{Test of acid number and base number}

Potentiometric determination of the acid number of bitumen was carried out with reference to "GB/T 18609-2011 Determination of acid number of crude oil by potentiometric titration" and "JTJ 052-2000 Standard Test Methods of Bitumen and Bituminous Mixtures for Highway Engineering. The method of detecting the total base number was carried out with reference to "SH /T 0251-93 (2004) Standard test method for base number of petroleum products (perchloric acid potentiometric method)".

\section{Emulsion preparation}

An aqueous phase was prepared by dispersing the emulsifier in water (the water was heated to $50^{\circ} \mathrm{C}$ ) and stirring for 10 min to ensure complete dissolution of the emulsifier and then adjust $\mathrm{pH}$ to 
a certain value. Asphalt emulsion was prepared by homogenizing 60 wt. $\%$ asphalt with 40 wt. $\%$ aqueous phase in a high-speed colloid mill.

\section{Storage Stability Test for Emulsified Asphalt}

This test method (ASTM D244) is useful for determining, in a comparatively short time, the storage stability of emulsified asphalt. It also covers the ability of emulsified asphalt to remain as a uniform dispersion during storage.

The emulsion samples were transferred into thin-walled glass tubes. They were held for $5 \mathrm{~d}$ at the temperatures $25{ }^{\circ} \mathrm{C}$. The solid content of the upper and lower parts were measured. Storage stability was calculated as:

$$
\mathrm{P}=S_{A}-S_{B}
$$

Where $\mathrm{P}$ refers to the storage stability, $\mathrm{S}_{\mathrm{A}}$ is the solid content of the lower part, and $\mathrm{S}_{\mathrm{B}}$ is the solid content of the upper part.

\section{Gray relation entropy analyses}

Gray system theory was formulated by Deng (1982)[11]. The theory can provide solutions for systems in which the model is uncertain, or the information incomplete. Besides, it provides an efficient solution to uncertain, multi-input, and discrete data problems. The relationship between machining parameters and performance can be revealed thus[12]. In the past 30 years the theory has been applied in many fields. Among them, the application of grey relational grade to the analysis of the properties of the asphalt has been reported[13-15].However, all these existing grey relation grades are generated by calculating the average value of consecutive point relation coefficients. This results in the following inevitable flaws including: firstly, the maximum value of point relation coefficients decides the trend of the general relation grade in the case of discrete distribution of point relation coefficients; secondly, the average value fails to reflect the characteristics of many point relation coefficients and fails to make fullest use of their abundant information. For example, in the weighted average method, whatever methods are employed to define the weights, some subjective factors will always be included. Especially when there is great number of nodes, it is too complicated process to decide the weights scientifically[16].In the face of the aforementioned limitations of previous research, this paper proposed the use of some properties such as grey relation entropy and entropy relation grade on the basis of grey relation entropy research, and then used them in the study of grey relation entropy's effects on the relationship between the oil-water interfacial properties and the chemical composition of bitumen. The definition of the gray relation entropy is as follows[17]:

(1) Formulation of relation grade supposed the system behaviour sequences were:

$$
\begin{aligned}
& X_{0}=\left(\chi_{0}(1), \chi_{0}(2), \ldots, \chi_{0}(n)\right. \\
& X_{1}=\left(\chi_{1}(1), \chi_{1}(2), \ldots, \chi_{1}(n)\right. \\
& \ldots \quad \ldots \quad \ldots \\
& X_{i}=\left(\chi_{2}(1), \chi_{2}(2), \ldots, \chi_{2}(n)\right. \\
& \ldots \quad \ldots \quad \ldots \\
& X_{m}=\left(\chi_{2}(1), \chi_{2}(2), \ldots, \chi_{2}(n)\right.
\end{aligned}
$$

Where $X_{0}$ is a reference sequence (namely the character sequence), $X_{i}(i=1,2, \ldots, m)$ is comparative sequence (namely the correlative sequence). To $\rho \in(0,1)$, order 


$$
\xi_{i}=\frac{\min _{\mathrm{i}=1, \mathrm{n}} \min _{\mathrm{k}=1, \mathrm{n}} \Delta_{\mathrm{i}}(\mathrm{k})+\rho \cdot \max _{\mathrm{i}=1, \mathrm{n}} \max _{\mathrm{k}=1, \mathrm{n}} \Delta_{\mathrm{i}}(\mathrm{k})}{\Delta_{\mathrm{i}}(\mathrm{k})+\rho \cdot \max _{i=1, \mathrm{n}} \max _{\mathrm{k}=1, \mathrm{n}} \Delta_{\mathrm{i}}(\mathrm{k})}
$$

Where, $\xi_{\mathrm{i}}\left\{\chi_{0}(\mathrm{k}), \chi_{\mathrm{i}}(\mathrm{k})\right\}$ is the grey related coefficient; $\Delta_{\mathrm{i}}(\mathrm{k})=\left|\mathrm{X}_{0}(\mathrm{k})-\mathrm{X}_{\mathrm{i}}(\mathrm{k})\right|$, $\min _{\mathrm{i}=1, \mathrm{nk}=1, \mathrm{n}} \Delta_{\mathrm{i}}(\mathrm{k})$ is the minimum difference of poles, $\max _{\mathrm{i}=1, \mathrm{n}} \max _{\mathrm{k}=1, \mathrm{n}} \Delta_{\mathrm{i}}(\mathrm{k})$ is the maximum difference of poles; and $\rho$ is the identification coefficient.

(2)Gray entropy

Definition 1: Suppose the grey connotation sequence was:

$X=\left(\chi_{1}, \chi_{2}, \ldots, \chi_{n}\right), \forall_{i}, \chi_{i} \geq 0$, and $\Sigma \chi_{i}=1$, then the following function is the grey entropy of sequence $\mathrm{X}$, with $\chi_{\mathrm{i}}$ being the attribute information.

$$
H \otimes(x)=-\sum_{i=1}^{m} x_{i} \ln x_{i}
$$

(3) Entropy relation grade

First, map the relation values of the reference sequence and the comparison sequence: $\xi\left(\chi_{0}, \chi_{i}\right), i=$ $1,2, \ldots, \mathrm{m}$. So

$$
\begin{array}{r}
P_{h}=\frac{\xi\left(x_{0}(h), x_{i}(h)\right)}{\sum_{k=1}^{n} \xi\left(x_{0}(h), x_{i}(h)\right)} \\
\mathrm{P}_{\mathrm{h}} \in \mathrm{P}_{\mathrm{i}} \quad(h=1,2, \ldots \mathrm{n})
\end{array}
$$

Then, according to the concept of grey entropy and the distribution mapping of grey relation coefficients, the grey relation entropy with property information can be expressed as:

$$
H\left(R_{i}\right)=-\sum_{h=1}^{n} p_{h} \ln p_{h}
$$

Knowing the distribution mapping of grey relation, $\mathrm{P}_{h} \geq 0$ and $\Sigma \mathrm{P}_{h}=1$ therefore the grey relation entropy becomes the grey entropy.

Definition 2: Suppose $\chi$ is the grey relation factor set, $\chi_{0}$ is the main behaviour column, $\chi_{i}$ is the reference column, $R_{i}$ is the relation coefficient column, $i \neq 0$, and $H\left(R_{i}\right)$ is the relation entropy. Here $\mathrm{H}_{\max }$ represents the maximum entropy of different information columns constituted by $\mathrm{m}$ attribute factors, and $\mathrm{H}_{\max }=\mathrm{m}$. Then we call the following formula the entropy relation degree of sequence $\chi_{\mathrm{i}}$

$$
\mathrm{E}\left(\chi_{\mathrm{i}}\right) \triangleq \mathrm{H}\left(\mathrm{R}_{\mathrm{i}}\right) / \mathrm{H}_{\max }
$$

(4) MATLAB ${ }^{\circledR}$ analysis program results

Taking the stability of emulsified asphalt as comparative sequences, and the chemical components of the bitumens as the reference sequences, the MATLAB ${ }^{\circledR}$ platform was used to construct the entropy relation degree, and in this calculation, the value of the identification coefficient $\rho$ was 0.5 .

\section{Results and Discussion}

\section{Effect of asphalt on the stability of emulsified asphalt}

Using four different asphalts as matrix asphalts, MQK-1D as emulsifier, and liquid soap with solute mass fractions of $0.5 \%-5.0 \%$ (based on emulsified asphalt) was configured and emulsified asphalts were prepared by colloidal mill with a $\mathrm{pH}=2$, asphalt temperature of $135{ }^{\circ} \mathrm{C}$ and liquid soap temperature at $50{ }^{\circ} \mathrm{C}$. The storage stability of emulsified asphalts in $5 \mathrm{~d}$ was then determined (Table 1). Table 1 shows that the stabilities of emulsified asphalts prepared by various asphalts were 
apparently different using the same preparation technology and conditions. This indicates that the interaction between each asphalt and emulsifier had different effects on the stability, which depended mainly on the components and properties of different asphalts. The storage stability was better with increasing emulsifier mass fractions, which reached a minimum value in the range of $2.0 \% \sim 3.0 \%$, whilst the stability was constant when the fractions of emulsifier kept increasing.

Table 1. Effect of asphalt on the stability of emulsified asphalt

\begin{tabular}{lllllllll}
\hline \multirow{2}{*}{ Asphalt } & \multicolumn{7}{c}{ stability/\% } \\
\cline { 2 - 9 } & $0.5 \%$ & $1 \%$ & $1.5 \%$ & $2 \%$ & $2.5 \%$ & $3.0 \%$ & $3.5 \%$ & $4.0 \%$ \\
\hline A1 & 21.58 & 13.58 & 4.20 & 2.86 & 2.70 & 2.51 & 2.40 & 2.33 \\
A2 & 30.41 & 14.43 & 3.71 & 2.32 & 2.07 & 1.93 & 2.14 & 2.00 \\
A3 & 16.33 & 15.67 & 10.9 & 3.62 & 3.28 & 2.65 & 2.51 & 2.43 \\
A4 & 18.17 & 15.49 & 12.9 & 4.61 & 4.12 & 3.52 & 3.13 & 3.02 \\
\hline
\end{tabular}

The Gray entropy correlation between the stability of emulsified asphalt and basic properties

The performance of an asphalt can be directly reflected by the penetration, softening point, ductility, its viscosity, etc., which are mainly used to characterize asphaltic pavement performance and ease and accuracy of construction thereof. Besides, acid value and alkali nitrogen value are two indices expressing the acidic, and alkaline, fractions in an asphalt. Research shows that, generally, the higher the acid, and alkali nitrogen values, contribute to the stronger the interfacial activity of the asphalt, the easier the asphalt emulsified, and the better stability of the emulsified asphalt [18]. Emulsified asphalt was prepared using same process technology and conditions, the stabilities of the four different emulsified asphalts stored for $5 \mathrm{~d}$ were determined, and the gray entropy correlations $(\mathrm{G})$ between the stability of emulsified asphalt and each asphalt's properties were analysed (see Table 2).

Table 2. The Gray entropy correlation between the stability of emulsified asphalt and basic properties

\begin{tabular}{cccccccc}
\hline Asphalt & Stability & $\begin{array}{c}\text { Acid } \\
\text { number }\end{array}$ & $\begin{array}{c}\text { Base } \\
\text { number }\end{array}$ & Density & $\begin{array}{c}\text { Viscosity } \\
\left(135^{\circ} \mathrm{C}\right)\end{array}$ & $\begin{array}{c}\text { Penetration } \\
\text { point }\end{array}$ \\
\hline A1 & 2.7 & 3.26 & 15.16 & 0.9962 & 705 & 72 & 47.9 \\
A2 & 2.07 & 1.38 & 13.61 & 1.0168 & 415 & 58 & 49 \\
A3 & 3.28 & 1.8 & 7.56 & 1.0097 & 358 & 63 & 46.7 \\
A4 & 4.12 & 1.43 & 8.01 & 1.0309 & 428 & 62 & 47.5 \\
G & & 0.9357 & 0.9966 & 0.9850 & 0.9859 & 0.9893 & 0.9856 \\
\hline
\end{tabular}

Table 2 shows that the gray entropy correlation between the stability of emulsified asphalt and an asphalt's basic properties decreased with alkali nitrogen value, penetration, viscosity, softening point, density, and acid value in that sequence.

However, there were no apparent regularities in the correlation between stability of emulsified asphalt and the basic properties of an asphalt. The stability of emulsified asphalt cannot be explained by any one particular property of the asphalt. The reason for this lay in the fact that the basic properties of an asphalt can embody both the extrinsic properties and macroscopic performance of an asphalt, while the composition and structural characteristics that determine the variance of stability of emulsified asphalt cannot be reflected. 


\section{The Gray entropy correlation between the stability of emulsified asphalt and four polar components}

In the system of emulsified asphalt behaviour, the contents of the four polar components of the asphalt have a close relationship with the interfacial activities thereof [18]. Research suggests that asphaltene shows the highest interfacial activity, and it mainly plays the role of a stabiliser in the formation of oil-in-water emulsions [19]; resin can both destabilise and stabilise the emulsion formed by asphaltene. The interaction between resin molecules is a major factor in determining whether or not resin molecule can resist the asphaltene's particular coalescence, and these weak interactions are beneficial to the stability of asphaltene [20,21]; saturates and aromatics can promote the interaction of resin and emulsifiers to reduce the oil-water interfacial tension of such a system [22]. The gray entropy correlation results of the stability of emulsified asphalt and the contents of the four asphalt components are shown in Table 3.

Table 3. The Gray entropy correlation between the stability of emulsified asphalt and four polar components

\begin{tabular}{ccccccc}
\hline Asphalt & Stability & Saturate & Aromatic & Resin* & Asphaltene & R\&At* $^{*}$ \\
\hline A1 & 2.7 & 27.35 & 32.78 & 39.03 & 0.77 & 39.8 \\
A2 & 2.07 & 21.37 & 28 & 43.74 & 6.88 & 50.62 \\
A3 & 3.28 & 27.34 & 33.42 & 25.47 & 13.77 & 39.24 \\
A4 & 4.12 & 19.01 & 43.2 & 22.73 & 15.06 & 37.79 \\
G & & 0.9787 & 0.9992 & 0.9852 & 0.9606 & 0.9971 \\
\hline
\end{tabular}

*The content of resin is calculated according difference. R\&At is the sum of Resin and Asphaltene.

As shows in Table3, the gray entropy correlation between the stability of emulsified asphalt and four polar components decreased with aromatic, R\&At, resin, saturate and asphaltene in that sequence.In the emulsification process, the interaction between emulsifier and asphalt components was an important factor affecting the degree of difficulty of asphalt emulsification. This interaction was dependent on the properties of the components present. There are more aromatic ring rigid structures in aromatic molecules with higher molecular polarity, and any interfacial film formed by these structures would be stronger; resin and asphaltene contain many heteroatomic groups with higher molecular polarity and higher interfacial activity, which are the main parts that interacted with the emulsifier in an oil-in-water emulsion; while saturates shows a lower molecular polarity and were potentially surface inert components. In emulsification, the higher the polarity of the components, the stronger the affinity between component molecules and emulsifier molecules, and the stronger the capability of the emulsifier in reducing the interfacial tension of components simulated oil, then the easier the asphalt emulsified the better stability of the emulsified asphalt.

In the disperse system of asphalt colloid however the contents of four-polar fractions was closely associated with its cleaning oil viscosity. In terms of the emulsion, the viscosity was directly dependent on the continuous phase viscosity. The higher the emulsion viscosity the better stability of emulsified asphalt. The existence of resin and asphaltene greatly increased the asphalt viscosity due to the resin and asphaltene, especially asphaltene, were the most polar components of asphalt composition. Both resin and asphaltene affected the polarity, the association between intramolecular and intermolecular were important even at low concentrations. The forces produced aromatic plane structures in the molecular units of resin and asphaltene which were stronger than the selfpolymerized associated asphaltene due to intermolecular forces[23]. Hence, in the association of emulsified asphalt stability and contents of asphalt four components the sum of resin and asphaltene 
contents was associated with the stability of grey entropy. The increase in contents sum of resin and asphltene the viscosity of emulsified asphalt increased (see Figure 1) and the stability improved.

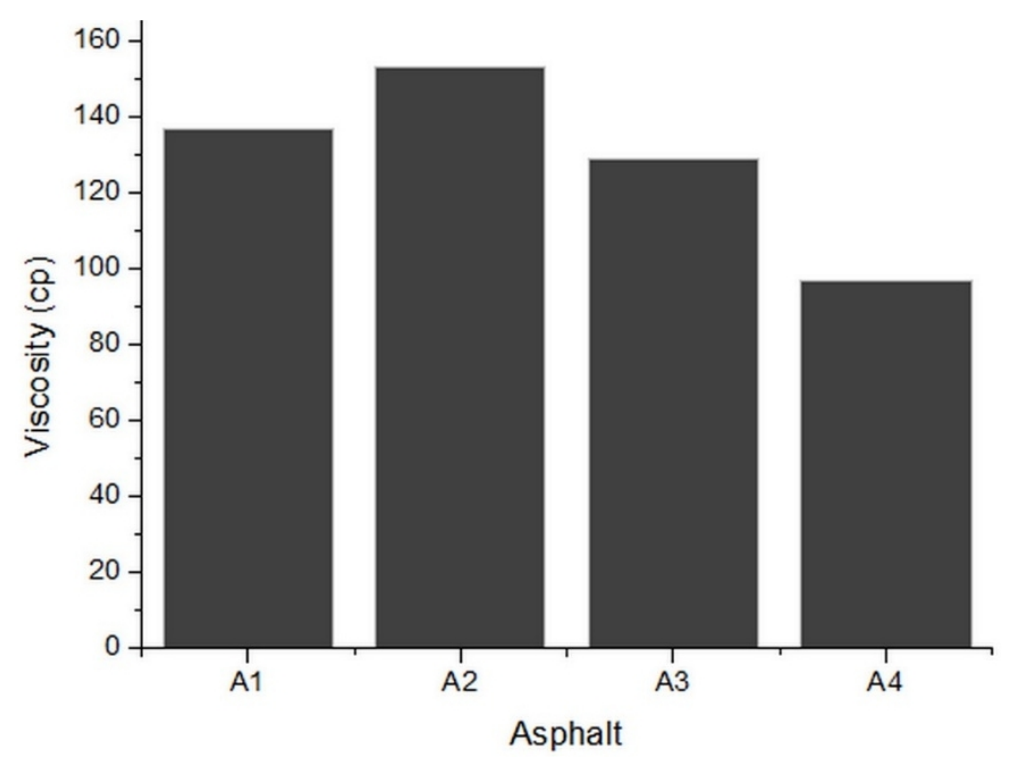

Fig.1. Effect of asphalt on viscosity of emulsified asphalt

The Gray entropy correlation between the stability of emulsified asphalt and elemental properties

Asphalt showed different interfacial activities in emulsified asphalt and different interactions with emulsifier on the oil-water interface. Its compositional structure's variance formed the main, inherent reason for the different interfacial activities. Therefore, performing correlation analysis between the composition structure and stability of emulsified asphalt was helpful to recognize, and quantify, the interaction law governing an asphalt and an emulsifier's systemic behavior. The gray entropy correlation results of the stability of emulsified asphalt and the composition of the asphalt factors are shown in Table 4.

Table 4.The Gray entropy correlation between the stability of emulsified asphalt and elemental properties

\begin{tabular}{ccccccccc}
\hline & & \multicolumn{7}{c}{ Elemental analysis } \\
\cline { 3 - 8 } Asphalt & Stability & \multirow{2}{*}{$\mathrm{H}$} & $\mathrm{C}$ & $\mathrm{N}$ & $\mathrm{S}$ & $\mathrm{O} *$ & Heteroatom* & $\begin{array}{c}\text { H/C atomic } \\
\text { ratio }\end{array}$ \\
\hline $\mathrm{A} 1$ & 2.7 & 11.62 & 86.48 & 0.77 & 0.22 & 0.91 & 1.9 & 1.602 \\
$\mathrm{~A} 2$ & 2.07 & 10.85 & 86.71 & 0.97 & 0.58 & 0.89 & 2.44 & 1.492 \\
$\mathrm{~A} 3$ & 3.28 & 10.29 & 84.64 & 0.71 & 4.05 & 0.31 & 5.07 & 1.449 \\
$\mathrm{~A} 4$ & 4.12 & 10.17 & 84.13 & 0.79 & 4.15 & 0.76 & 5.7 & 1.441 \\
$\mathrm{G}$ & & 0.9813 & 0.9840 & 0.9964 & 0.9973 & 0.9882 & 0.9978 & 0.9808 \\
\hline
\end{tabular}

*The content of oxygen is calculated according to difference. The content of heteroatom is the sum of oxygen, sulfur and nitrogen.

As shows in Table 4, the gray entropy correlation between interface pressure and elemental properties decreased with heteroatom, $\mathrm{S} 、 \mathrm{~N} 、 \mathrm{O} 、 \mathrm{C} 、 \mathrm{H} 、 \mathrm{H} / \mathrm{C}$ atomic ratio in that sequence.

Increasing the heteroatom content, such as $\mathrm{S}, \mathrm{N}$, and $\mathrm{O}$, the stability of emulsified asphalt also trended to increase. This was because the high contents of organic heteroatom such as $\mathrm{O}, \mathrm{N}, \mathrm{S}$ etc. in 
asphalt resulted in the more polar groups in the asphalt. The strong polarity of the asphalt composition ensures higher hydrophilicity and making adsorption at the interface easier. Finally, the interfacial activities was stronger. Meanwhile, Ling Cheng et al. found that, the higher organic heteroatom contents in the elementary composition of asphalt, the higher asphalt viscosity, and the better stability of emulsified asphalt. Moreover, organic heteroatom was mainly enriched in resin and asphaltene, making them the most polar components, thus explaining that the higher contents of resin and asphaltene in asphalt, the stronger interfacial activities of asphalt making the emulsification of asphalt easier, and hence better stability.

\section{The Gray entropy correlation between the stability of emulsified and average structural unit parameter}

The average structure of asphalt can be derived through information such as: factor composition, average molecular weight, $1 \mathrm{H}-\mathrm{NMR}$, etc. Table 5 and Table 6 lists the hydrogen-to-carbon ratio of the asphalts' polar components and associated 1H-NMR basic data.

Table 5. Chemical shifts for the different type of protons

\begin{tabular}{ccc}
\hline Symbol & Type of proton & Chemical shifts $(\mathrm{ppm})$ \\
\hline $\mathrm{H}_{\mathrm{A}}$ & Aromatic hydrogen & $6.0-9.0$ \\
$\mathrm{H}_{\alpha}$ & Hydrogen on $\alpha$ carbons to aromatic rings & $2.0-4.0$ \\
$\mathrm{H}_{\beta}$ & Hydrogen on $\beta$ carbons to aromatic rings & $1.0-2.0$ \\
$\mathrm{H}_{\gamma}$ & Hydrogen on $\gamma$ carbons or $\mathrm{CH}_{3}$ terminal of & $0-1.0$ \\
\hline
\end{tabular}

Table 6.The basic data of magnetic

\begin{tabular}{cccccccc}
\hline Asphalt & $\begin{array}{c}\text { Average molecular } \\
\text { weight }\end{array}$ & $\mathrm{C} / \%$ & $\mathrm{H} / \mathrm{C}$ & $\mathrm{H}_{\mathrm{A}}$ & $\mathrm{H}_{\alpha}$ & $\mathrm{H}_{\beta}$ & $\mathrm{H}_{\gamma}$ \\
\hline $\mathrm{A} 1$ & 837.3 & 86.71 & 1.492 & 0.07 & 0.133 & 0.6 & 0.197 \\
$\mathrm{~A} 2$ & 1143.1 & 86.48 & 1.602 & 0.042 & 0.081 & 0.622 & 0.255 \\
$\mathrm{~A} 3$ & 853.3 & 84.13 & 1.441 & 0.07 & 0.169 & 0.556 & 0.21 \\
$\mathrm{~A} 4$ & 744.1 & 84.64 & 1.449 & 0.07 & 0.164 & 0.567 & 0.2 \\
\hline
\end{tabular}

Table 7. The Gray entropy correlation between the stability of emulsified and average structural unit parameter

\begin{tabular}{cccccccc}
\hline Asphalt & Stability & $\mathrm{f}_{\mathrm{A}}$ & $\mathrm{f}_{\mathrm{N}}$ & $\mathrm{f}_{\mathrm{P}}$ & $\mathrm{BI}$ & HAU/CA & $\sigma$ \\
\hline A & 2.7 & 0.2277 & 0.1651 & 0.6073 & 0.2418 & 0.0044 & 0.4909 \\
$\mathrm{~A} 2$ & 2.07 & 0.3018 & 0.1907 & 0.5075 & 0.1792 & 0.0075 & 0.4872 \\
$\mathrm{~A} 3$ & 3.28 & 0.3219 & 0.2308 & 0.4473 & 0.1816 & 0.0090 & 0.5376 \\
A4 & 4.12 & 0.3257 & 0.2220 & 0.4523 & 0.1888 & 0.0079 & 0.5454 \\
G & & 0.9611 & 0.9780 & 0.9887 & 0.9874 & 0.9930 & 0.9675 \\
\hline
\end{tabular}

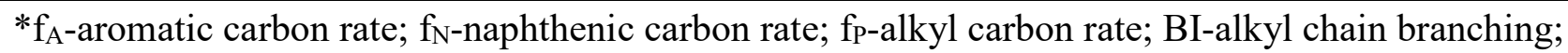
HAU/CA-aromatic ring condensation degree; $\sigma$ - substituted aromatic - carbon ratio;

As shown in reference [25], the average structural unit parameters of bitumen were computed by the theory of improved B-L method. And the gray entropy correlation between interfacial pressure and average structural unit parameter are shown in Table 7.

As shows in Table 7, the gray entropy correlation between interface pressure and elemental properties decreased with aromatic ring condensation degree, alkyl carbon rate, alkyl chain branching, naphthenic carbon rate, substituted aromatic - carbon ratio and aromatic carbon rate in that sequence. 
However, Table 7 shows that there were no apparent regularities between the structure of emulsified asphalt and the average structural unit parameters. This may be due to the average structural unit parameters of asphalt obtained from a plurality of idealized assumption do not exactly reflect the difference in the composition structure. At the same time, the stability of emulsified asphalt was affected by factors, such as the composition and properties of asphalt, certain structural units could not used to characterize the stability of emulsified asphalt.

\section{Conclusions}

The correlation between the stability of emulsified asphalt and an asphalt's compositional structure, interfacial activities, and asphalt properties, was analysed using gray correlation entropy analysis. Meanwhile, the governing relationship for the composition properties of an asphalt with the stability of emulsified asphalt was discussed. The basic properties of asphalt potentially reflected the macroproperties thereof, but cannot characterise the stability of emulsified asphalt . The gray entropy correlation between stability of emulsified asphalt and the four polar components of asphalt were (in decreasing order of influence:)aromatic, R\&A,resin, saturates and asphaltene. The higher the R\&A content, the better the stability of emulsified asphalt.Heteroatomic constituents were among the composition factors of asphalt showing the maximum gray correlation with the stability of emulsified asphalt. Also, they were the main factors affecting the stability of emulsified asphalt. The higher the contents of heteroatomic constituents the better the stability of emulsified asphalt. The average structural unit parameters of asphalt cannot be used to characterize the stability of emulsified asphalt since they show no obvious correlation.

\section{Acknowledgements}

This work was financially supported by the National Natural Science Foundation of China (No. 51608511).We would like to acknowledge many coworkers, students, and laboratory assistants for providing technical help on instrument analysis. Thanks to Dr. Edward C. Mignot, Shandong University, for linguistic advice.

\section{References}

[1] Gorman, Jacinta L, Crawford, Russell J, Harding, Ian H. Bitumen emulsions in road construction: a review. Road \& transport research, 2004; 13: 25-38.

[2] Salomon D R. Asphalt Emulsion Technology. Transportation Research Circular E-C102, 2006.

[3] Wang FZ, Liu YP, Zhang YH, Hu SG. Experimental study on the stability of asphalt emulsion for CA mortar by laser diffraction technique. Constr Build Mater 2012; 28(1): 117-121.

[4] Gingras JP, Tanguy PA, Mariotti S, Chaverot P. Effect of process parameters on bitumen emulsions. Chem Eng Process 2005; 44(9): 979-986.

[5] Jerzy K, Bengt K. On the formation and stability of concentrated water-in-oil emulsions, aprons. Colloids Surf. 1990; 50: 131-140.

[6] Sherman P, Parkinson C. Mechanism of temperature induced phase inversion in $\mathrm{O} / \mathrm{W}$ emulsions stabilized by O/W and W/O emulsifier blends. Colloid Polym. Sci. 1978; 63: 10-14.

[7] Ostberg G, Bergenstahl B, Hulden M. Influence of emulsifier on the formation of alkyd emulsions. Colloid Surf. A-Physicochem. Eng. Asp. 1995;94(2/3):161-171. 
[8] Zhao PH, Fan WY, Tian CF, Dong S. Study On the Stability of Emulsified Asphalt for CA Mortar. Petroleum Processing and Petrochemicals 2012; 43(1):62-67.

[9] Verbich SV, Dukhin SS, Tarovski A, Holt Q, Saether Q, Sjobom J. Evaluation of stability ratio in oil-in-water emulsions. Colloid Surf. A-Physicochem. Eng. Asp. 1997; 123-124, 209-223.

[10] Spiecker PM, Gawrys KL, Trail CB. Effects of petroleum resins on asphaltene aggregation and water-in-oil emulsion formation . Colloid Surf. A-Physicochem. Eng. Asp. 2003;220: 9-27.

[11] Deng JL. Huazhong University of Science \& Technology Press Co., Ltd, 1987.

[12] Liu HM, Zhang GQ, Yao DH, Li HB. Application of the theory of grey relation degree to dynamic shear test. Petroleum Asphalt 2000; 14(1):8-11.

[13] Li LH. Analysis of relation degree of asphalt performance index. Petroleum asphalt 2000; 14(3):7-10.

[14] Zhao XZ, Guo JC, Liao KJ, Cong YF, Dai YL. Analysis of chemical make -up and material properties of regenerated asphalt by grey relation entropy. Science \& Technology In Chemical Industry 2005; 13(1):38-40.

[15] Gao SS. Asphalt composition influencing its viscosity and its grey correlation analysis. Petroleum Asphalt 2008;22(2):66-68.

[16] Zhang QS, Guo XJ, Deng JL. Grey relation entropy analysis method. Systems Engineering theory \& Practice 1996; 8: 8-12.

[17] Cheng L, Yang L, Luo TT, Lei JM, Lan M. Analysis of the gray correlation entropy of viscosity to chemical components in heavy crude oil dispersion system. Journal of Xi'an Shiyou University (Natural Science Edition) 2007; 22(3), 92-95,140.

[18] Bai JM. Study on the influence of heavy crude components and emulsifiers on the interfacial properties. Qing Dao: College of Chemistry and Chemical Enigneering in China University of Petroleum 2009.

[19]Chen YX, Chen J, Pan CS, Li G, Xiao XQ. Influence of asphaltenes and resins on the stability of heavy crude emulsions. Applied Chemical Industry 2009; 38(2):194-196, 20.

[20] Pereira JC, Lopez I, Salas R, Silva F, Fernandez C, Urb C, López JC,Resins: The Molecules Responsible for the Stability/Instability Phenomena of Asphaltenes. Energy\& Fuel 2007;21(3):13171321.

[21] Jean LS, Raquel A, Aton OD. Properties of resins extracted from boscan crude oil and their effect on the stability phenomena of asphaltenes. Energy\& Fuel 2007; 21(3):1317-1321.

[21] Salager JL, Antón R, Dávila A. Properties of resins extracted from boscan crude oil and their effect on the stability of asphaltenes in boscan and hamaca crude oils. Energy\& Fuel 1999; $13(2): 309-314$.

[22] Fan WY, Bai JM, Ren CG, Zhang TY, Nan GZ and Li SP. Influence of interaction among Liaohe heavy oil components on interfacial tension of heavy oil-in-water emulsion.Journal of China University of Petroleum (Edition of Natural Sciences) 2008;32(4):123-126.

[23] Wattana P, Fogler H S. Characterization of polarity-based asphaltene subfractions. Energy \& Fuels 2005; 19(1):101-110. 